\title{
Super-twisting SMC for MPPT and grid-connected WECS based on SCIG
}

\author{
Bouhenna Amina $^{1}$, Khodja Mohammed ${ }^{2}$, Merabet Boulouiha Houari ${ }^{3}$ \\ ${ }^{1}$ Institute of Science and Technology, Department of Electrical Engineering, LGIDD Laboratory, Ahmed Zabana \\ University Center of Relizane, Relizane, Algeria \\ ${ }^{2}$ Department of Electrical Engineering, Ahmed Zabana University Center of Relizane, Relizane, Algeria \\ ${ }^{3}$ Department of Electrical Engineering, National Polytechnic School of Oran - Maurice Audin, ENPO-MA, Oran, Algeria
}

\begin{tabular}{|c|c|}
\hline Article Info & ABSTRACT \\
\hline Article history: & This paper proposes a high-order sliding mode control (HO-SMC) with the \\
\hline Received Jul 21, 2020 & $\begin{array}{l}\text { super-twisting (ST) algorithm for maximum power point tracking (MPPT) } \\
\text { and grid-connected wind energy conversion system (WECS), based on }\end{array}$ \\
\hline Revised Jan 21, 2021 & squirrel-cage induction generator (SCIG). The main features of this control \\
\hline Accepted Feb 11, 2021 & $\begin{array}{l}\text { strategy are attenuation of the chattering phenomenon inherent in first-order } \\
\text { sliding mode control and its robustness against external and internal }\end{array}$ \\
\hline Keywords: & $\begin{array}{l}\text { disturbances encountered by the wind power system. The simulation is } \\
\text { carried out under SimPowerSystems of MATLAB/Simulink to evaluate the }\end{array}$ \\
\hline IRFOC & performance and effectiveness of the proposed control compared with \\
\hline MPPT & different scenarios of disturbances, a fluctuating wind speed, a grid voltage \\
\hline SCIG & drop, and parametric variations. \\
\hline
\end{tabular}

ST algorithm

Sim power systems

WECS

\section{Corresponding Author:}

Bouhenna Amina

Institute of Science and Technology, Department of Electrical Engineering

Laboratoire de Génie Industriel et Développement Durable (LGIDD)

Ahmed Zabana University Center of Relizane

P.O Box, 48000, Bourmadia, Relizane, Algeria

Email: amina.bouhenna@cu-relizane.dz
This is an open access article under the $\underline{C C B Y-S A}$ license.

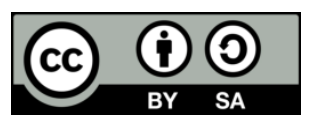

\section{INTRODUCTION}

Electricity generation from the kinetic energy of the wind is the most widespread renewable energy source in the world. This development is due to the increase in source demand for clean and non-polluting electrical energy. However, the integration of more electricity production from wind turbines may cause some disturbances with a negative impact on the stability of the grid and the quality of the electrical energy produced [1]. Therefore, the development of new control strategies for the wind power system is becoming a necessity, to mitigate the problems related to the quality of this energy and to ensure that the WECS remains insensible to internal and external disturbances, which degrade the system performance and may even lead to instability. The powers control in WECS is complex since it is related to several variables such as wind speed fluctuations, parametric variations of the induction generator, which can make a linear control ineffective, and the sudden drop of voltage at the grid since it produces high peak currents on the electrical circuits, so the converters may be damaged. To solve these problems, and to ensure the robustness of the system against various disturbances, many works are proposed in the literature [2]-[6]. The researchers in [5] propose a direct torque control (DTC) to estimate the torque and flux following the desired speed, while the integral back-stepping controllers (IBC) for the control of the machine side converter (MSC) in WECS is used to regulate the speed of the permanent magnet synchronous generator (PSMG) in [6]. Among the different 
nonlinear control schemes, the authors in [7]-[9] have introduced sliding mode control (SMC), which could improve the dynamic of the WECS. The SMC is considered robust against external and internal disturbances, but it produces undesirable chattering and does not stabilize perforce in a finite time. Thus, in [9] using nonlinear perturbation observers for WECS based on doubly fed induction generator (DFIG), a robust SMC is suggested to improve fault ride-through (FRT), while a high-order SMC, which comprises second-order (SO-SMC), is developed to mitigate chattering, hence reducing mechanical stresses and ensured better performances [10]-[14]. Indeed, a maximum power point tracking (MPPT) control based on voltage-mode second-order fast terminal SMC (SO-FTSMC) is proposed to optimize the performance in the power extraction from PMSG based on WECS [12]. Whereas the regulation of the power produced by the generator for a DFIG based wind turbine (WT) is studied using a SO-SMC [13]. Using an HO-SMC applied in the grid side converter (GSC) in case of grid faults, the FRT ability of a DFIG based WT is assessed in [14].

The super-twisting sliding mode control (ST-SMC) is an especial case of the HO-SMC. It was initiated first in [15] for the servo-control system of relative degree equal to one. Its main advantage is that it needs only information on the sliding surface and not its derivative. It has been used in several publications to improve the control of WECS [16]-[19]. In [20], the ST sliding mode direct power control is suggested to control the active and reactive powers of Brushless-DFIG (BDFIG) without using an inner current loop regulator and phase-locked loop. Furthermore, a robust ST-SMC for WECS is described in [21] to optimize the aerodynamic torque and the extracted power. To regulate the DC-link voltage, especially in grid fault conditions, [22] presents the ST-SMC for the gearless high-inertia PMSG-based wind turbine. The same approach with MPPT control of WECS based on DFIG is proved able to control the active power, track the maximum power point and regulate the reactive power [23], while in [24], an HO-SMC based on the ST algorithm of the BDFIG based WECS, is proposed for the stator side converter control. However, the gridside converter (GSC) is supervised by classical PI control. The integral ST-SMC (ISTSMC) is used in [25] to eliminate chattering and improve the robustness and convergence of the induction machine speed.

Compared with these recently published researches, this paper proposes a new robust control strategy of the global system, allowing the extraction of the maximum power from the wind at low and medium wind speed ranges, the optimization of the active power transfer to the grid with a unity power factor and a fixed DC-link voltage. Unlike the previously cited works, which used different controls for MSC and GSC, the novelty of this paper is the injection of ST-SMC into the overall control system, since the variable speed WECS based on SCIG is a variable structure system and subject to many constraints, difficult to control using general concepts. In addition, the association of the WECS based SCIG became very attractive with the improvement of power electronics and lower cost of squirrel-cage machines, which are of robust construction and requiring less maintenance. The contribution of the paper is to improve greatly the effectiveness of the WECS based on SCIG with MPPT control by implementing the ST-SMC for the regulation of the induction generator speed, the DC-link voltage as well as the direct and quadrature currents of the grid. The proposed control strategy ensures the reduction of the chattering phenomenon inherent in first-order SMC and the robustness of the system against external and internal disturbances such as the effects of fluctuating wind speed, grid fault conditions, and parametric variations.

The paper is organized as follows: Section 2 describes the wind turbine modeling with the MPPT control and the indirect rotor field-oriented control (IRFOC) of SCIG. Section 3 presents the implementation of ST-SMC. Section 4 shows the simulation results of the performance and the effectiveness of the proposed control strategy compared with the conventional PI controller, which is the most popular strategy implemented in many industrial applications and Fuzzy Logic PI controller under SimPowerSystems of MATLAB/Simulink. Finally, in section 5, conclusions are presented.

\section{PROPOSED CONFIGURATION OF THE SYSTEM}

Variable speed WT configuration based on SCIG with the control system is shown in Figure 1. A back-to-back (BTB) converters topology of control based on IGBTs (Insulated Gate Bipolar Transistors) in the wind power system based on SCIG, with few electronics components, presents a technical advantage through large controllability capacity [1]. A three-bladed wind turbine is coupled to SCIG through a gearbox while the stator of SCIG is connected to the grid via two BTB converters. On one side, the ST-SMC regulates the speed of SCIG by adjusting the generator torque to track the speed reference value obtained by the MPPT control. Then, the IRFOC of Figure 2 generates the switching signals based on the technique of hysteresis current regulator that regulates the SCIG voltage and achieves the maximum power extraction. On another side, the SCIG's output is converted into DC by MSC, which charges a capacitor C. The grid side objectives are to maintain the DC-link voltage on the capacitor fixed to ensure connection to the electrical grid with a unity power factor and maximum active power transfer. The power flow between the grid and the GSC, 
driven by the PWM technique, is regulated through the $\mathrm{d}-\mathrm{q}$ axis grid currents and the DC-link voltage control based on the ST-SMC.

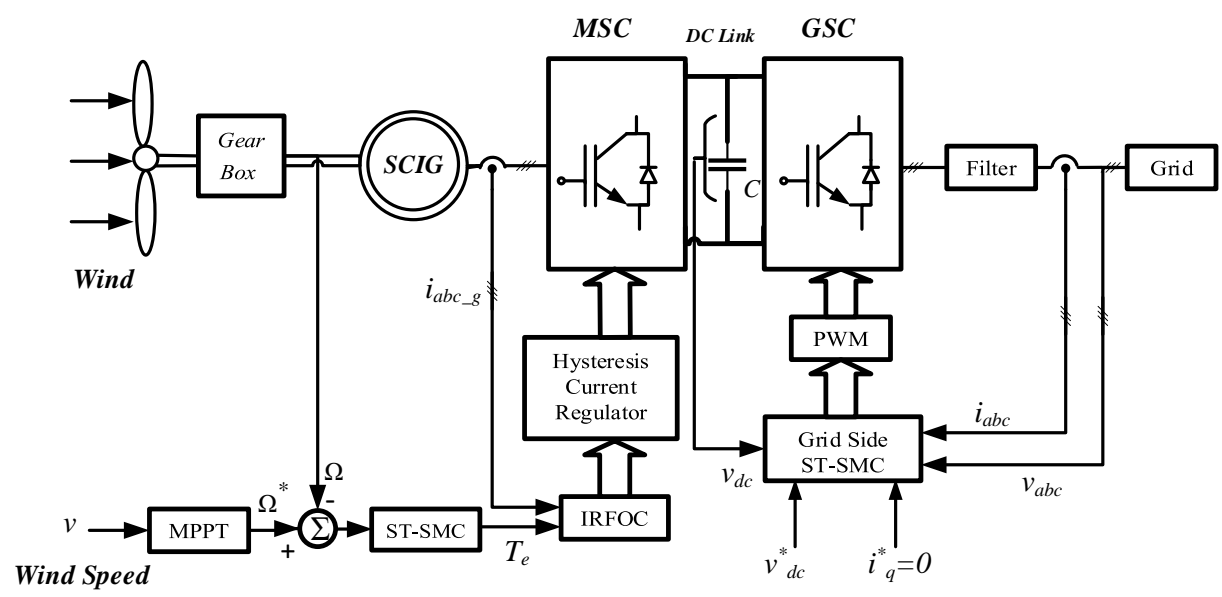

Figure 1. Wind turbine system based on SCIG with the control system

\subsection{Modeling of the wind turbine with MPPT control}

The mechanical output power of the wind-turbine is given by the (1) [26]-[28]:

$$
P_{t}=\frac{\rho \pi R^{2}}{2} C_{p}(\lambda, \beta) v^{3}
$$

where $C_{p}$ is the coefficient of power conversion and $v$ is the wind speed $(\mathrm{m} / \mathrm{s})$. To model $C_{p}(\lambda, \beta)$, which is a function of the tip speed ratio $\lambda$ and the blade pitch angle $\beta$, the (2), (3), (4) can be used:

$$
\begin{aligned}
& C_{p}(\lambda, \beta)=0.5176\left(\frac{116}{\lambda_{i}}-0.4 \beta-5\right) e^{\frac{21}{\lambda_{i}}}+0.0068 \lambda \\
& \frac{1}{\lambda_{i}}=\frac{1}{\lambda+0.08 \beta}-\frac{0.035}{\beta^{3}+1} \\
& \lambda=\frac{R \Omega_{\mathrm{t}}}{v}
\end{aligned}
$$

where $\Omega_{\mathrm{t}}(\mathrm{rad} / \mathrm{s})$ denotes the mechanical speed of the turbine. The rotor radius $R=10.5 \mathrm{~m}$ and the air density $\rho=1.225 \mathrm{Kg} / \mathrm{m}^{3}$. The maximum value of $C_{p},\left(C_{p}^{\mathcal{M}}=0.48\right)$ is achieved for $\beta=0$ and the optimal tip speed ratio $\lambda^{\sigma}=8.1$.

The maximum power $P_{t}^{\mathcal{M}}$ from the wind is obtained through the MPPT control as (5):

$$
P_{t}^{\mathcal{M}}=K_{P}^{\sigma} \Omega_{t}^{\sigma 3}
$$

where $\Omega_{t}^{\sigma}$ is the optimal mechanical speed and $K_{P}^{\sigma}$ is an optimal gain.

\subsection{Indirect rotor field oriented control of SCIG}

The (6) and (7) describe the stator voltages components $\left(V_{s d}, V_{s q}\right)$ in the two-axis d-q reference frame, where $\omega_{s}$ and $\omega_{r}$ denote respectively the stator synchronous speed and the rotor angular speed, $i_{s d}$ and $i_{s q}$ represent the stator currents components in d-q reference frame. The rotor flux $\phi_{r}$ in (9) is oriented on the $\mathrm{d}$-axis such as $\phi_{r d}=\phi_{r}$ and $\phi_{r q}=0$ [26]. $T_{e}$ is the electromagnetic torque of the SCIG. The block diagram of IRFOC of SCIG is presented in Figure 2.

$$
V_{s d}=R_{s} i_{s d}+\sigma L_{s} \frac{d i_{s d}}{d t}-\sigma L_{s} \omega_{s} i_{s q}
$$




$$
\begin{aligned}
& V_{s q}=R_{s} i_{s q}+\sigma L_{s} \frac{d i_{s q}}{d t}+\sigma L_{s} \omega_{s} i_{s d}+\frac{L_{m}}{L_{r}} \omega_{s} \phi_{r} \\
& \omega_{r}=\frac{L_{m}}{T_{r} \phi_{r}} i_{s q} ; \omega_{s}=\omega_{r}+\mathrm{p} \Omega ; \dot{\theta}_{s}=\omega_{s} ; T_{r}=\frac{L_{r}}{R_{r}} \\
& L_{m} i_{s d}=\frac{L_{r}}{R_{r}} \dot{\phi}_{r}+\phi_{r} \\
& T_{e}=\frac{1.5 p L_{m} \phi_{r}}{L_{r}} i_{s q}
\end{aligned}
$$

The SCIG's parameters are: stator resistance $R_{s}=14.85 \mathrm{~m} \Omega$, rotor resistance $R_{r}=9.295 \mathrm{~m} \Omega$, rotor leakage inductance $L_{l r}=0.3027 \mathrm{mH}$, stator leakage inductance $L_{l s}=0.3027 \mathrm{mH}$, cyclic mutual inductance $L_{m}=10.46 \mathrm{mH}$, dispersion coefficient $\sigma=0.055$, inertia $J=3.1 \mathrm{Kg} / \mathrm{m}^{2}$, viscous friction coefficient $f=$

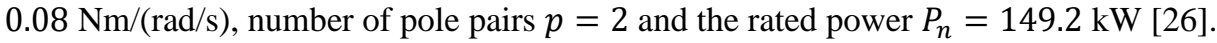

In the steady state, (9) becomes (11):

$$
i_{s d}^{c}=\frac{1}{L_{m}} \phi_{r}
$$

The defluxing bloc in Figure 2, is defined by (12) where $\phi_{n}$ denotes the nominal flux value and $\Omega_{\mathrm{n}}$ is the nominal rotor speed.

$$
\phi_{r}=\left\{\begin{array}{c}
\phi_{n},|\Omega| \leq \Omega_{\mathrm{n}} \\
\frac{\Omega_{\mathrm{n}}}{|\Omega|} \phi_{n},|\Omega|>\Omega_{\mathrm{n}}
\end{array}\right.
$$

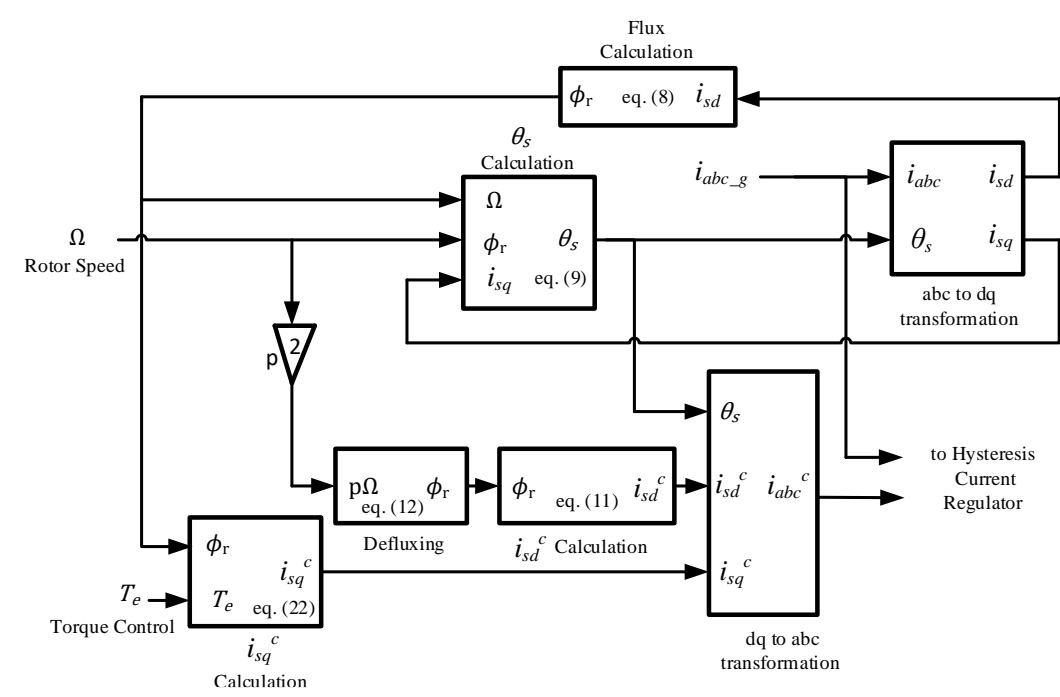

Figure 2. IRFOC representation of SCIG

\section{CONTROL STRATEGIES OF THE GENERATOR AND CONVERTERS}

\subsection{High-order sliding mode control with the ST algorithm steps}

The following steps describe how the algorithm works.

Step 1: Write the nonlinear dynamics of the system as follows: $\dot{\eta}=f(t, \eta, u)$ where $t, \eta, u$ are respectively the time, the state variable and the input of the system.

Step 2: Choose the sliding surface $S=\eta-\eta^{*}$ to achieve the control objective by following the optimal reference $\eta^{*}$.

Step 3: Define the first derivative $\dot{S}$.

Step 4: Write the second derivative $\ddot{S}$ in the following form $\ddot{S}=\Gamma(t, \eta)+\Psi(t, \eta) \dot{u}(t)$.

Step 5: Use the HO-SMC with the ST algorithm under the transition conditions: $k_{m} \leq|\Psi| \leq K_{M},|\Gamma| \leq C_{i}$, $\alpha>C_{i} / k_{m}$ and $\gamma>\sqrt{2\left(\alpha K_{M}+C_{i}\right)} / k_{m}$ where $C_{i}, k_{m}, K_{\mathrm{M}}$ are positives constants [13], [14], [16]-[25]. 


$$
\left\{\begin{array}{c}
u(t)=u_{1}(t)-\gamma \sqrt{|S|} \operatorname{sign}(S) \\
\dot{u}_{1}(t)=-\alpha \cdot \operatorname{sign}(S)
\end{array}\right.
$$

Step 6: Implement (13) and choose by simulations tests, the control gains $\alpha$ and $\gamma$, which verify the conditions cited in step 5.

This control law contains two terms. The first term is a discontinuous function of the sliding surface, and the other is a continuous function of its derivative. This algorithm does not require any information on the sliding surface derivative [13], [14], [24].

The discontinuous control input $\dot{u}(t)$ is acting on $\ddot{S}$ to make $S=\dot{S}=0$ in a finite time with $u(t)$ a continuous input. Therefore, the chattering in systems is reduced, providing high precision and avoiding significant mechanical forces while maintaining the robustness of the first-sliding mode control.

\subsection{Implementation of ST-SMC for the control of the generator speed}

The purpose of this sub-section is to present the strategy of the HO-SMC with the ST algorithm to regulate optimally the SCIG's speed. The sliding variable $S_{\Omega_{t}}$ is chosen to achieve the control objective by following an optimal reference speed $\Omega_{\mathrm{t}}^{*}$ provided by the MPPT control.

$$
\begin{aligned}
& S_{\Omega_{\mathrm{t}}}=\Omega_{\mathrm{t}}-\Omega_{\mathrm{t}}^{*} \\
& \Omega_{\mathrm{t}}^{*}=\frac{\lambda^{\sigma}}{R} \cdot v
\end{aligned}
$$

The derivative of the sliding variable is:

$$
\dot{S}_{\Omega_{\mathrm{t}}}=\dot{\Omega}_{\mathrm{t}}-\dot{\Omega}_{\mathrm{t}}^{*}
$$

The derivative of the speed $\Omega_{\mathrm{t}}$ is obtained from the mechanical equation of the wind turbine:

$$
\dot{\Omega}_{\mathrm{t}}=\frac{1}{J}\left(T_{t}-T_{e}-f \cdot \Omega_{\mathrm{t}}\right)
$$

where $T_{t}$ is the turbine torque. Then, the derivative of the sliding variable can be re-written as:

$$
\dot{S}_{\Omega_{\mathrm{t}}}=\frac{1}{J}\left(T_{t}-T_{e}-f \cdot \Omega_{\mathrm{t}}\right)-\dot{\Omega}_{\mathrm{t}}^{*}
$$

The second derivative of the sliding surface $\ddot{S}_{\Omega_{t}}$ is as (19):

$$
\ddot{S}_{\Omega_{\mathrm{t}}}=\Gamma_{\Omega_{\mathrm{t}}}+\Psi_{\Omega_{\mathrm{t}}} \cdot \dot{T}_{e}
$$

where the smooth functions are defined by:

$$
\Gamma_{\Omega_{\mathrm{t}}}=\frac{\dot{T}_{t}}{J}-\frac{f}{J} \cdot \dot{\Omega}_{\mathrm{t}}-\ddot{\Omega}_{\mathrm{t}}^{*} ; \Psi_{\Omega_{\mathrm{t}}}=-1 / J
$$

Following the step 4, the control input is $u_{\Omega}(t)=T_{e}$ allowing the implementation of the ST-SMC in the presence of uncertainties and disturbances [13], [14], [16] with the following transition conditions: $\left|\Gamma_{\Omega_{\mathrm{t}}}\right| \leq \mathrm{C}_{\Omega} ; k_{\Omega m} \leq\left|\Psi_{\Omega_{\mathrm{t}}}\right| \leq K_{\Omega M}$ where $C_{\Omega}, k_{\Omega m}, K_{\Omega M}$ are positive constants.

The following equations held: $\Omega_{\mathrm{t}}=\Omega_{\mathrm{t}}^{*}$, and $\Omega=\Omega^{*}$ since $\Omega=\mathrm{G} \cdot \Omega_{\mathrm{t}}, \forall t>t_{f}$ where $t_{f}$ is a finite time and $\mathrm{G}$ is the multiplier of the gearbox. The control input $T_{e}$ can be expressed by (21) where the values of the control gains are $\alpha_{\Omega}=5000, \gamma_{\Omega}=3000$.

$$
\left\{\begin{aligned}
u_{\Omega}(t)= & T_{e}=u_{\Omega 1}(t)-\gamma_{\Omega} \sqrt{\left|S_{\Omega_{t}}\right|} \operatorname{sign}\left(S_{\Omega_{t}}\right) \\
& \dot{u}_{\Omega 1}(t)=-\alpha_{\Omega} \cdot \operatorname{sign}\left(S_{\Omega_{t}}\right)
\end{aligned}\right.
$$

From (10), the quadrature current $i_{s q}^{c}$ obtained indirectly from the torque control $T_{e}$, is: 


$$
i_{s q}^{c}=\left(\frac{L_{r}}{1.5 p L_{m} \phi_{r}}\right) T_{e}
$$

Therefore, the equation (22) explains how the proposed control input $T_{e}$ of (21) can achieve the main objective of the MSC control. Indeed, the IRFOC, represented in Figures 1 and 2, uses the (22) with (11) to generate the switching signals to send to MSC, through the hysteresis current regulator. This strategy allows the regulation of SCIG voltage and extraction of maximum power.

\subsection{Implementation of ST-SMC algorithm for the control of the DC-link voltage and the grid currents}

The control approach on the grid side is shown in Figure 3. Two ST-SMC manage the cascaded loop. The outer loop regulates the DC-link voltage $v_{d c}$ while the inner loop adjusts the direct current of the grid $i_{d}$, which controls the active power P. The reference direct current $i_{d}^{*}$ is the output of the outer ST-SMC. The quadrature component current $i_{q}$, which controls the reactive power $\mathrm{Q}$ is also regulated by a ST-SMC. The reference quadrature current $i_{q}^{*}$ is set to zero to achieve a unity power factor and the DC-link voltage reference is set to $1000 \mathrm{~V}$. The PWM uses the output of the current regulators $v_{g d}$ and $v_{g q}$ compensated by two decoupling terms, to generate the switching signals and drive the GSC. Thereby, the proposed control system produces the maximum active power to the grid. In order to synchronize the WECS to the grid voltages, a phase-locked loop (PLL) is used to estimate the instantaneous phase $\theta$. The purpose is to transform the grid signals in the d-q reference frame in order to synchronize the phase of this reference frame with the rotating field of the electrical grid. The Park's transformations allow adequate control of the system on the grid side [24], [26].

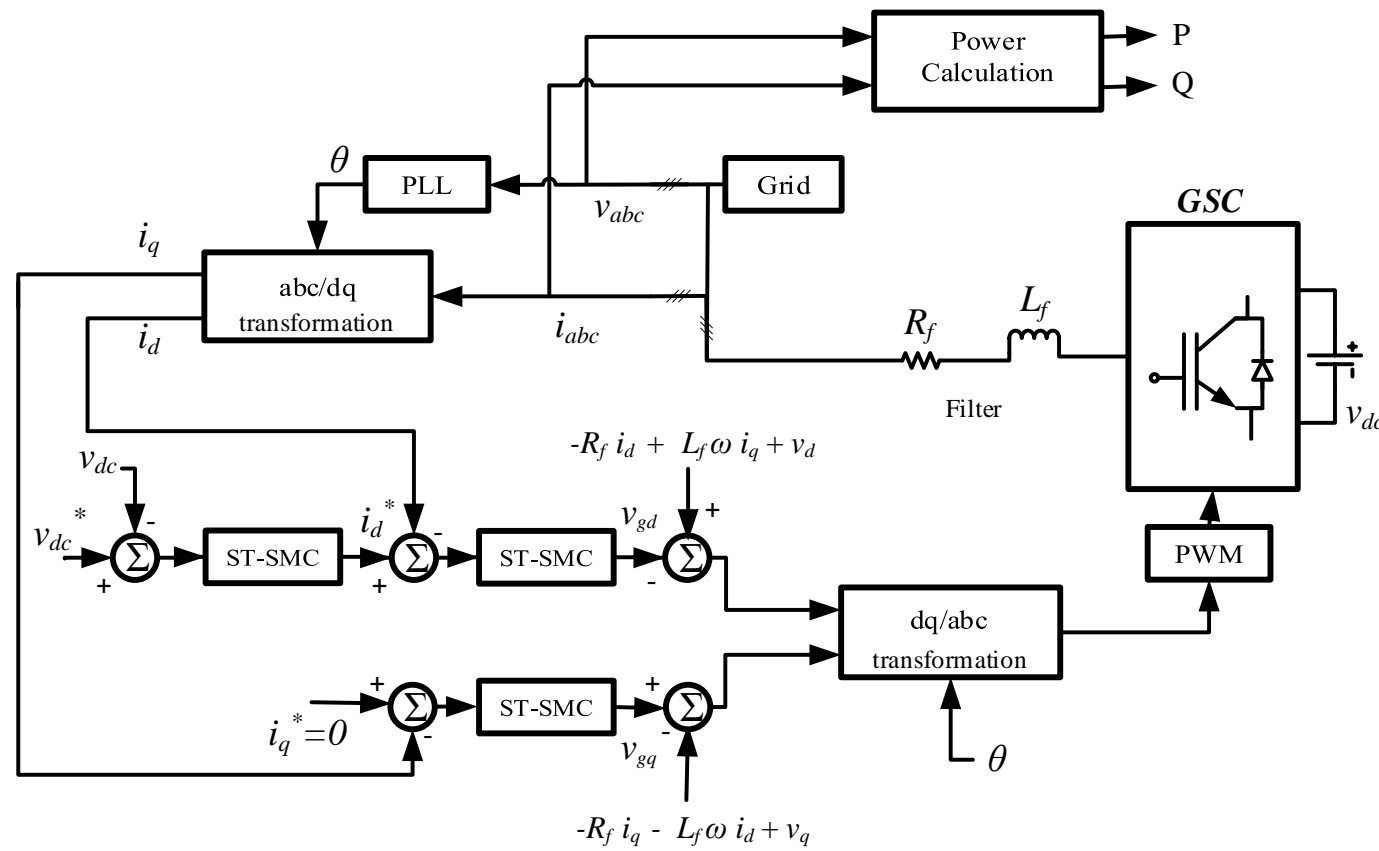

Figure 3. Scheme of the control of grid currents and DC-link voltage

The voltage equations, across the inductor $L_{f}$ in the d-q reference frame [24], [28], are as (23):

$$
\left\{\begin{array}{c}
L_{f} \frac{d i_{d}(t)}{d t}=-R_{f} i_{d}+L_{f} \omega i_{q}+v_{d}-v_{g d} \\
L_{f} \frac{d i_{q}(t)}{d t}=-\left(-R_{f} i_{q}-L_{f} \omega i_{d}+v_{q}\right)+v_{g q}
\end{array}\right.
$$

where the filter inductance and resistance are respectively $L_{f}=2 \mathrm{mH}, R_{f}=0.2 \Omega ; v_{d}, v_{q}$ represent the grid voltages components; $i_{d}, i_{q}$ are the grid currents components. The nominal grid voltage and frequency are $V_{s n}=460 \mathrm{~V}, f_{g n}=50 \mathrm{~Hz}$ [26]. Figure 4 shows the scheme for regulating the DC-link voltage $v_{d c}$, which varies according to the power exchanged between the turbine and the grid. Its dynamic is represented by (24): 


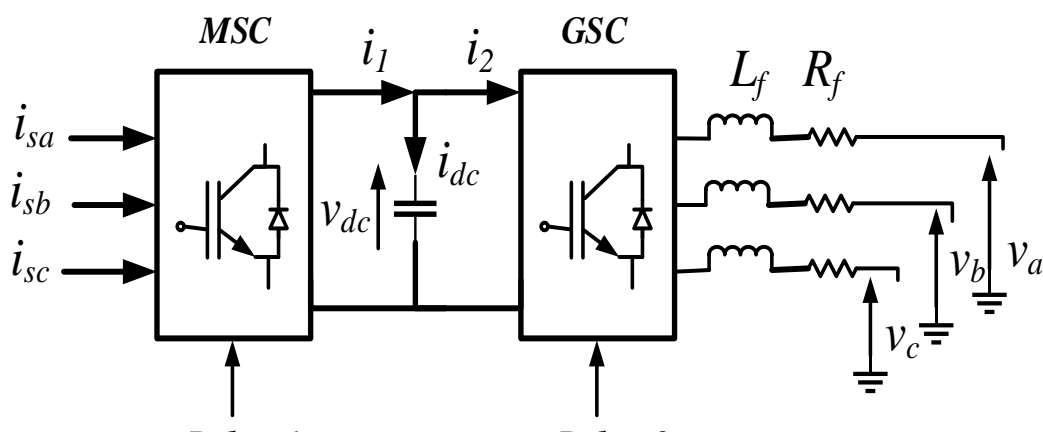

Pulsos 1

Pulsos?

Figure 4. Scheme of the DC-link

$C \frac{d v_{d c}}{d t}=i_{1}-i_{2}$

The sliding variables $S_{v}=v_{d c}-v_{d c}^{*}, S_{d}=i_{d}-i_{d}^{*}$ and $S_{q}=i_{q}-i_{q}^{*}$ are chosen to achieve the control objectives by following optimal references defined respectively by the DC-link voltage $v_{d c}^{*}$, the direct current $i_{d}^{*}$ and the quadrature current $i_{q}^{*}$. Then, the derivatives of the sliding variables are:

$$
\left\{\begin{array}{c}
\dot{S}_{v}=\frac{1}{C}\left(i_{1}-i_{2}\right)-\dot{v}_{d c}^{*} \\
\dot{S}_{d}=\left(\frac{1}{L_{f}} v_{d}-\frac{R_{f}}{L_{f}} i_{d}+\omega i_{q}-\frac{1}{L_{f}} v_{g d}\right)-\frac{d i_{d}^{*}}{d t} \\
\dot{S}_{q}=\left(\frac{1}{L_{f}} v_{q}-\frac{R_{f}}{L_{f}} i_{q}-\omega i_{d}-\frac{1}{L_{f}} v_{g q}\right)-\frac{d i_{q}^{*}}{d t}
\end{array}\right.
$$

The power balance gives [24]:

$v_{d c} \cdot i_{2}=v_{d} \cdot i_{d}+v_{q} \cdot i_{q}$

The second derivatives of the sliding surface obtained from (25) and (26) are as follows:

$$
\left\{\begin{array}{l}
\ddot{S}_{v}=\Gamma_{v}+\Psi_{v} \cdot \frac{d i_{d}}{d t} \\
\ddot{S}_{d}=\Gamma_{d}+\Psi_{d} \cdot \dot{v}_{g d} \\
\ddot{S}_{q}=\Gamma_{q}+\Psi_{q} \cdot \dot{v}_{g q}
\end{array}\right.
$$

where the smooth functions are defined by:

$$
\left\{\begin{array}{c}
\Gamma_{v}=\dot{\varrho}_{v} ; \varrho_{v}=\frac{1}{c} i_{1}-\dot{v}_{d c}^{*}-\frac{v_{q} i_{q}}{C \cdot v_{d c}} ; \Psi_{v}=-\frac{v_{d}}{C \cdot v_{d c}} \\
\Gamma_{d}=\dot{\varrho}_{d} ; \varrho_{d}=\frac{1}{L_{f}} v_{d}+\omega i_{q}-\frac{d i_{d}^{*}}{d t}-\frac{R_{f}}{L_{f}} i_{d} ; \Psi_{d}=-\frac{1}{L_{f}} \\
\Gamma_{q}=\dot{\varrho}_{q} ; \varrho_{q}=\frac{1}{L_{f}} v_{q}-\frac{d i_{q}^{*}}{d t}-\frac{R_{f}}{L_{f}} i_{q}-\omega i_{d} ; \Psi_{q}=-\frac{1}{L_{f}}
\end{array}\right.
$$

The ST-SMC is implemented in the presence of uncertainties and disturbances [13], [14], [16] with the following transition conditions: $\left|\Gamma_{v}\right| \leq C_{v}, k_{m v} \leq\left|\Psi_{v}\right| \leq K_{M v},\left|\Gamma_{d}\right| \leq C_{d}, k_{m d} \leq\left|\Psi_{d}\right| \leq K_{M d}$, $\left|\Gamma_{q}\right| \leq C_{q}, k_{m q} \leq\left|\Psi_{q}\right| \leq K_{M q}$ where $C_{v}, K_{m v}, K_{M v}, C_{d}, K_{m d}, K_{M d}, C_{q}, K_{m q}, K_{M q}$ are positives constants.

Thus, $v_{d c}=v_{d c}^{*}, \forall t>t_{f v}, i_{d}=i_{d}^{*}, \forall t>t_{f d}$ and $i_{q}=i_{q}^{*}, \forall t>t_{f q}$ where $t_{f v}, t_{f d}$ and $t_{f q}$ are finite times. The controls inputs $v_{v}(t), v_{g d}(t)$ and $v_{g q}(t)$, represented in Figure 3, are as follows: 


$$
\left\{\begin{array}{c}
v_{v}(t)=i_{d}^{*}(t)=v_{v 1}(t)-\gamma_{v} \sqrt{\left|S_{v}\right|} \operatorname{sign}\left(S_{v}\right) \\
\dot{v}_{v 1}(t)=-\alpha_{v} \operatorname{sign}\left(S_{v}\right) \\
v_{g d}(t)=v_{d 1}(t)-\gamma_{d} \sqrt{\left|S_{d}\right|} \operatorname{sign}\left(S_{d}\right) \\
\dot{v}_{d 1}(t)=-\alpha_{d} \operatorname{sign}\left(S_{d}\right) \\
v_{g q}(t)=v_{q 1}(t)-\gamma_{q} \sqrt{\left|S_{q}\right|} \operatorname{sign}\left(S_{q}\right) \\
\dot{v}_{q 1}(t)=-\alpha_{q} \operatorname{sign}\left(S_{q}\right)
\end{array}\right.
$$

The values of the control gains are: $\alpha_{v}=2, \gamma_{v}=0.5, \alpha_{d}=10, \gamma_{d}=100, \alpha_{q}=150, \gamma_{q}=100$.

\section{RESULTS AND DISCUSSION}

The simulation of the HO-SMC with the ST algorithm for the WECS based on SCIG is performed using SimPowerSystems of MATLAB/Simulink. The settings of all ST-SMC parameters, which verify the conditions cited in step 5, are chosen by simulations tests. Moreover, in Figure 3, the cascade loop is managed by two ST-SMC, which consists of two imbricate loops where the inner loop is faster than the outer loop. The structure of PI controllers is $G_{P I}(s)=k_{P}+k_{i} / s$ where $k_{P \Omega}=5000, k_{i \Omega}=10, k_{p v}=8, k_{i v}=$ $400, k_{P d}=5, k_{i d}=500, k_{P q}=5, k_{i q}=500$. Three scenarios are considered to validate the performance and the feasibility of the ST-SMC compared to conventional and fuzzy logic (FL) PI controllers. Fuzzy GainScheduling controller used for MSC operates with Fuzzy rules and exploits human knowledge and experience in control to set the PI controller parameters [29], while the Fuzzy Adaptive PI controller applied for GSC, are an association of conventional PI controller and fuzzy logic controller (FLC) [30]. It takes advantages of PI controller and the adaptive capability of FLC. The first case represented in Figure 5(a) proposes a fluctuating wind, operating under normal conditions while in the second case, represented in Figure 5(b), a sudden drop in grid voltage of $30 \%$ in the time interval between 2 and $4 \mathrm{~s}$, at wind nominal speed of $12 \mathrm{~m} / \mathrm{s}$ is simulated. In the third case, parametric variations of the SCIG are introduced at wind nominal speed.

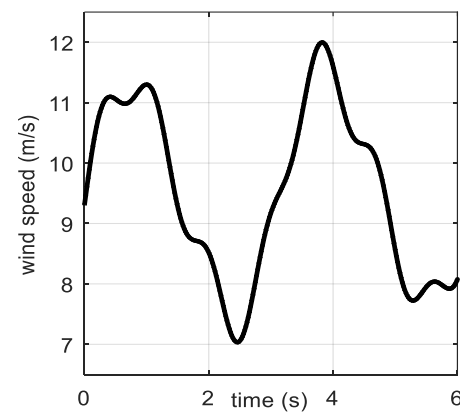

(a)

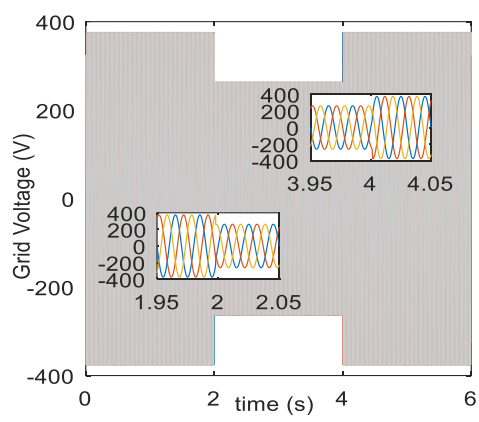

(b)

Figure 5. Curves of fluctuating wind speed and grid voltage drop, (a) Fluctuating wind speed, (b) Grid voltage drop

\subsection{Fluctuating wind speed}

The simulation is done in $6 \mathrm{~s}$, and the results are presented in Figures 6 and 7. Figure 6(a) shows the fast dynamic response of the speed and a very good performance for the trajectory tracking, with high accuracy despite wind speed variations for the ST-SMC compared to PI controllers. That means the error between the actual and reference speed is zero, which ensured the ideal transfer of the maximum active power established by the MPPT control to the grid. Figure 6(b) shows the ST-SMC performances compared to the conventional PI controllers and the Fuzzy adaptive PI controller. Indeed, firstly a smoother curve is obtained since chattering is mitigated hence reducing mechanical stresses. Secondly, DC-link voltage robustness against wind fluctuating is ensured, which guaranteed that all the active power is instantly transferred to the grid. Third, the low peak value of the ST-SMC is clearly visible, thus preserving the safety of the electrical system. 


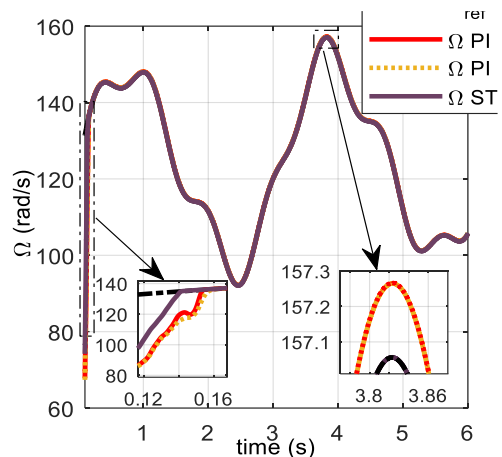

(a)

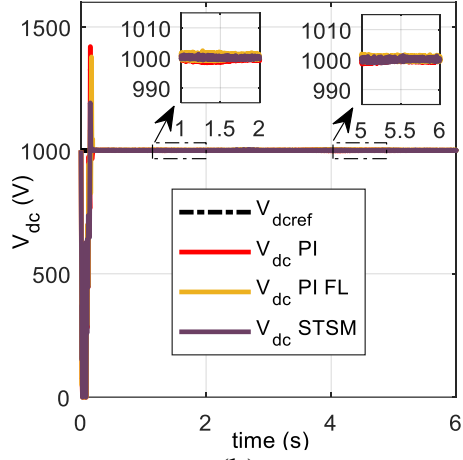

(b)

Figure 6. Curves of the generator speed and the DC-link voltage in case of fluctuating wind, (a) Generator speed, (b) DC-link voltage

In Figure 7(b), a zero reactive power is provided by the ST-SMC, regardless of ripples produced by PWM, avoiding, therefore, altering the quality of the grid, while the two PI controllers exhibited fluctuations around zero. Using the MPPT strategy, the waveform of the active power of Figure 7(a), delivered to the grid is similar to the wind speed curve of Figure 5(a), which means a small change in the wind induces a significant change in the output active power.

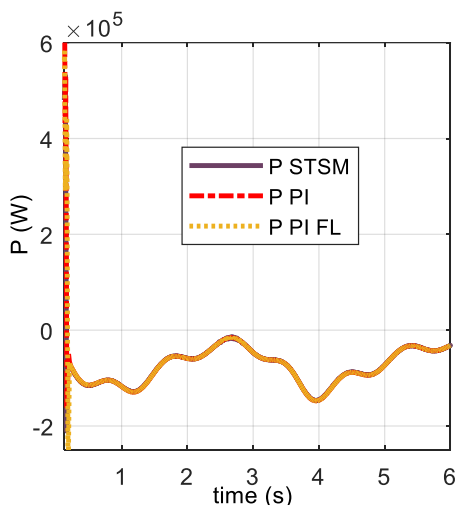

(a)

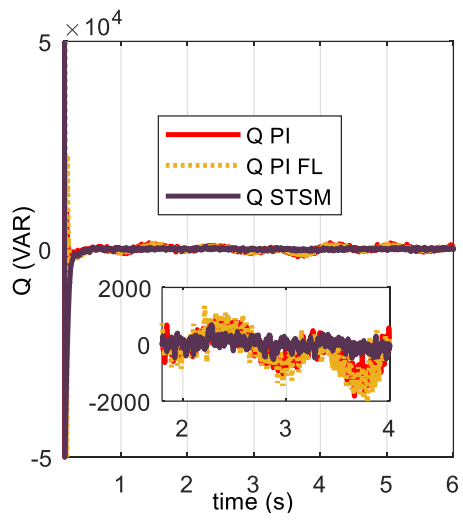

(b)

Figure 7. Curves of the active and reactive powers in case of fluctuating wind,

(a) Active power, (b) Reactive power

\subsection{Grid voltage drop}

The simulation of a grid voltage drops up to $30 \%$ of the grid nominal voltage is carried out in $6 \mathrm{~s}$ between $t \in[2],[4] \mathrm{s}$. The results are presented in Figures 8 and 9. For the speed tracking of Figure 8(a), the ST-SMC can track the MPPT optimal speed with higher accuracy and fast dynamic response as compared to the conventional PI and the Fuzzy Logic PI controllers. In Figures 8(b), 9(a), and 9(b), corresponding respectively to the DC-link voltage, the active power, and the reactive power, the ST-SMC provides a smoother curve compared to PI controllers, particularly at times of sudden variations in grid voltage. Furthermore, in Figure 8(b) the peak value of the DC-link voltage reaches $1500 \mathrm{~V}$ for the conventional PI controller, while for Fuzzy adaptive PI controller and ST-SMC, it is less than $1250 \mathrm{~V}$. Note that the highpeak value of the DC-link voltage, caused by the conventional PI controller, can damage the converters. 


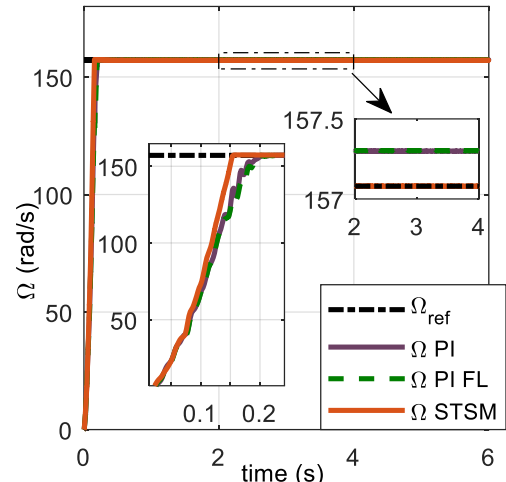

(a)

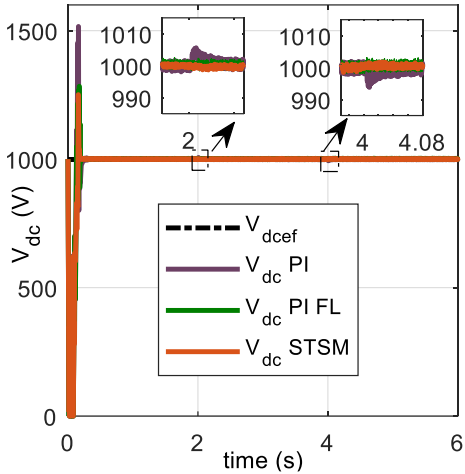

(b)

Figure 8. Curves of the generator speed and the DC-link voltage in case of drop in grid voltage,

(a) Generator speed, (b) DC-link voltage

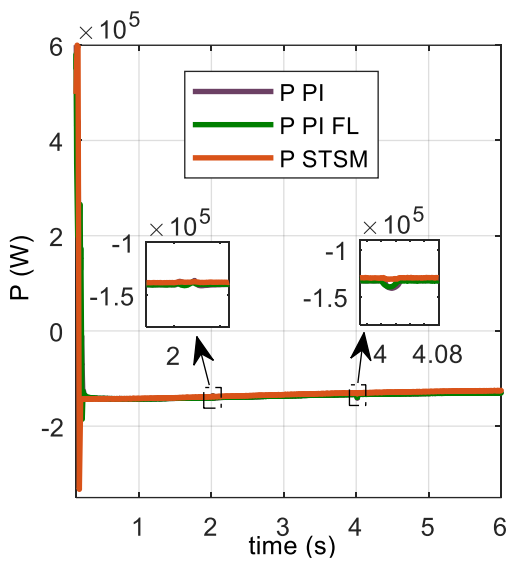

(a)

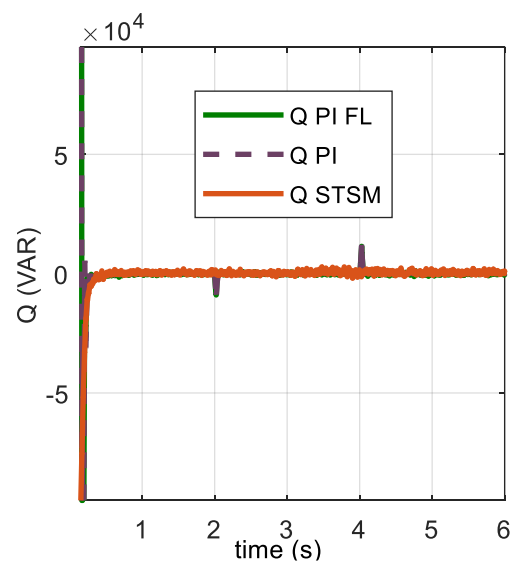

(b)

Figure 9. Curves of the active and reactive powers in case of drop in grid voltage,

(a) Active power, (b) Reactive power

\subsection{Parameters variations}

This scenario uses uncertainties including variations in the rotor resistance, the inertial moment, and the friction coefficient of the SCIG up to $80 \%$ of their nominal values between $t \in[0,2] \mathrm{s}$. The simulation results are presented in Figures 10 and 11. As shown in Figure 10(a), in a steady state, a speed error remains for the two PI controllers, unlike the ST-SMC. During the transient response, the rise time of the speed towards the reference speed, for the conventional and Fuzzy PI controllers increased considerably compared with the ST-SMC. This leads to slowness in the power transfer from the wind turbine to the grid as shown in Figures 11(a) and 11(b). Moreover, in Figure 10(b), repetitive peak values appear on the DC-link voltage for both PI controllers, while the ST-SMC has a smaller overshot than the conventional PI controller does. Therefore, the PI controllers have poor performance during transient operation and speed inaccuracies in steady state, compared to the ST-SMC.

The ST-SMC implementation on the overall wind power system is a notable contribution and a new aspect of the obtained results. This nonlinear control made it possible to guarantee the same good performances in the three disturbance scenarios, which are fluctuating wind speed, grid voltage drops and parameters variations of the SCIG. These results are, therefore, non-obvious to obtain simultaneously. 


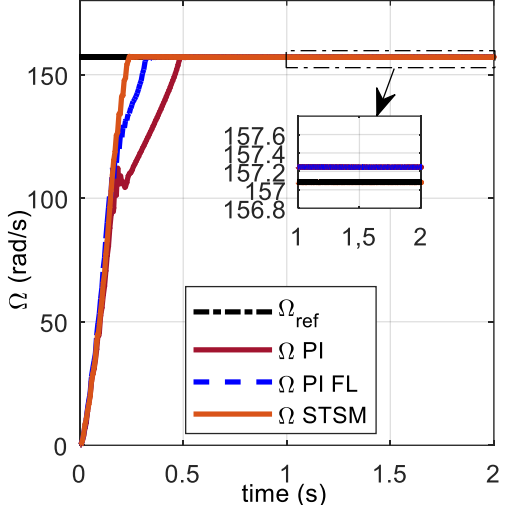

(a)

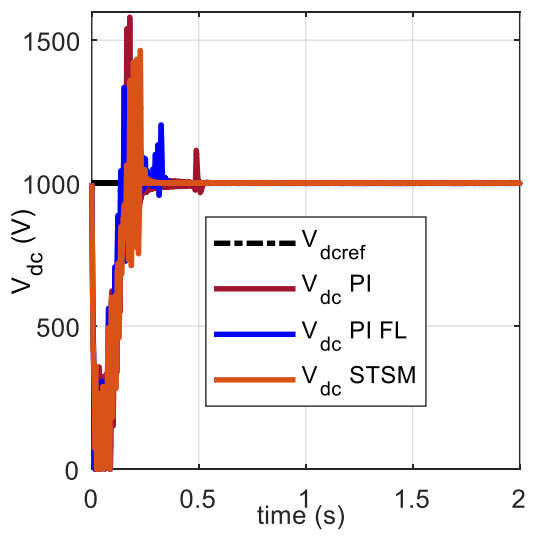

(b)

Figure 10. Curves of the generator speed and the DC-link voltage in case of parametric variations, (a) Generator speed, (b) DC-link voltage

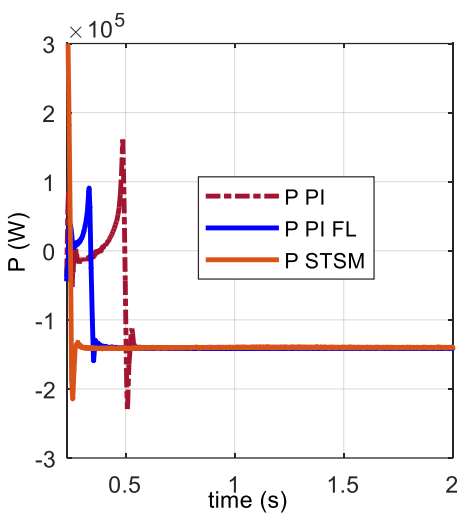

(a)

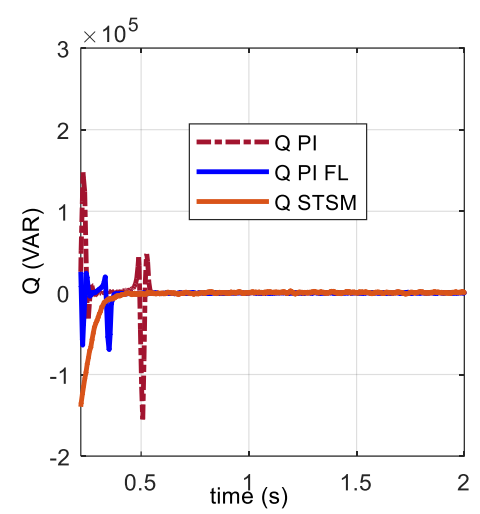

(b)

Figure 11. Curves of the active and reactive powers in case of parametric variations,

(a) Active power, (b) Reactive power

\section{CONCLUSION}

This paper is concerned with the HO-SMC with the ST algorithm of a WECS using a SCIG. This control strategy designed for MSC and GSC is successfully proposed, to best meet the expectations of optimizing the extraction of the power available in the wind via the MPPT control, as well as the connection to grid services, and to ensure the robustness of the overall system against parameters uncertainties and disturbing effects. Also, as expected chattering is reduced and smoother control is observed.

After an evaluation of the robustness and effectiveness of the proposed ST-SMC, in different operating conditions of the WECS, the superiority of the ST-SMC performance compared to related earlier research, the conventional and the Fuzzy Logic PI controllers, have been proved, despite wind speed fluctuations, grid voltage drop and parametric variations of the SCIG, and constitutes a significant contribution in the improvement of WECS.

The results obtained under SimPowerSystems of MATLAB/Simulink, demonstrate that the ST-SMC proposed approach achieves good stability and dynamic performance. It can rapidly reach the MPPT under internal and external disturbances with a high-accuracy speed tracking and a fast convergence. These allow, respectively, the perfect conversion of the maximum power established by the MPPT control and the instantaneous transfer of the active power extracted from the wind turbine to the grid, which is guaranteed by keeping the DC-link voltage constant. Furthermore, the reactive power is maintained to zero in order not to impair the quality of the grid. The proposed WECS - SCIG - ST-SMC strategy has the advantage of simple structure and can be an innovative and practical solution for the WECS to maintain the quality of electrical energy supply. 


\section{REFERENCES}

[1] F. Blaabjedg and D.M. Ionel, "Renewable energy devices and systems with simulations in Matlab and ansys," CRC Press, Taylor \& Francis Group, chap. 10, pp. 251-265, 2017, http://www.crcpress.com.

[2] M. Z. M. Tumari et al., "A modified grey wolf optimizer for improving wind plant energy production," Indonesian Journal of Electrical Engineering and Computer Science, vol. 18, no. 3, pp. 1123-1129, 2020.

[3] P. K. Ray et al., "Stability Improvement in Power System Integrated with WECS Using Dolphin Echolocation Optimized Hybrid PID Plus FLC-Based PSS," Innovation in Electrical Power Engineering, Communication, and Computing Technology, vol. 630, pp. 697-708, 2020.

[4] B. Yang et al., "Adaptive fractional-order PID control of PMSG-based wind energy conversion system for MPPT using linear observers," Int Trans ElectrEnerg Syst.., vol. 29, pp. 1-18, 2018.

[5] H. A. Aroussi et al., "Improvement of direct torque control applied to doubly fed induction motor under variable speed," International Journal of Power Electronics and Drive System (IJPEDS), vol. 11, no. 1, pp. 97-106, 2020.

[6] X. Makhad et al., "Nonlinear control of WECS based on PMSG for optimal power extraction," International Journal of Electronics and Communication Engineering (IJCECE), vol. 6, pp. 2815-2823, 2020.

[7] J. Hostettler and X. Wang, "Sliding mode control of a permanent magnet synchronous generator for variable speed wind energy conversion systems," Journal Systems Science \& Control Engineering, vol. 3, pp. 453-459, 2015.

[8] L. Hu et al., "Sliding mode extremum seeking control based on improved invasive weed optimization for MPPT in wind energy conversion system," Appl Energy, vol. 248, pp. 567-75, 2019.

[9] B. Yang et al., "Robust sliding-mode control of wind energy conversion systems for optimal power extraction via nonlinear perturbation observers," Appl Energy, vol. 210, pp. 711-723, 2017.

[10] X. Liu et al., "Second-order sliding mode control for power optimization of DFIG-based variable speed wind turbine," IET Renew Power Gener, vol. 11, pp. 408-418, 2016.

[11] M. Abolvafaei and S. Ganjefar, "Maximum power extraction from a wind turbine using second-order fast terminal sliding mode control," Renew Energy, vol. 139, pp. 1437-1446, 2019.

[12] E.H. Dursun et al., "Second-order sliding mode voltage-regulator for improving MPPT efficiency of PMSG-based WECS," Electrical Power and Energy Systems, vol. 121, pp.1-9, 2020.

[13] B. Beltran et al., "Second order sliding mode control of a doubly fed induction generator driven wind turbine," IEEE Transactions on Energy Conversion, vol. 27, pp. 261-269, 2012.

[14] M. Benbouzid et al., "Second-order sliding mode control for DFIG-based wind turbines fault ride-through capability enhancement," ISA Transactions, vol. 53, pp. 827-833, 2014.

[15] A. Levant, "Sliding order and sliding accuracy in sliding mode control," Int J Control, vol. 58, pp. 1247-1263, 1993.

[16] A. Levant, "Principles of 2-sliding mode design," Automatica, vol. 43, pp. 576-586, 2007.

[17] C.A. Evangelista et al., "Multivariable 2-sliding mode control for a wind energy system based on a double fed induction generator," International Journal of Hydrogen Energy, vol. 37, pp. 10070-10075, 2012.

[18] I. Yaichi et al., "Super-twisting Sliding Mode Control of a Doubly-fed Induction Generator Based on the SVM Strategy," Periodica Polytechnica Electrical Engineering and Computer Science, vol. 63, pp. 178-190, 2019.

[19] B. Kelkoul, "Stability analysis and study between Classical Sliding Mode Control (SMC) and Super Twisting Algorithm (STA) for Doubly Fed Induction Generator (DFIG) under Wind turbine," Energy, vol. 214, pp. 1-32, 2020, https://doi.org/10.1016/j.energy.2020.118871.

[20] R. Sadeghi et al., "Super-Twisting Sliding Mode Direct Power Control of Brushless Doubly Fed Induction Generator," IEEE Transactions on Industrial Electronics, pp. 1-10, 2018, https://doi.org/10.1109/TIE.2018.2818672.

[21] S. Boubzizi et al., "Comparative study of three types of controllers for DFIG in wind energy conversion system," Protection and Control of Modern Power Systems, vol. 3, pp. 3-21, 2018.

[22] N. Mojtaba et al., "Super-Twisting Sliding Mode Control for Gearless PMSG-Based Wind Turbine," Hindawi Complexity, vol. 2019, pp. 1-15, 2019, https://doi.org/10.1155/2019/6141607.

[23] L. Xinyi et al., "Super Twisting Sliding Mode MPPT Control of an IM based Wind Energy Conversion System," $4^{\text {th }}$ IEEE, International Conference on Electrical Engineering, 2015, pp. 1-5, doi:10.1109/INTEE.2015.7416793.

[24] O. Moussa et al., "Super-twisting sliding mode control for brushless doubly fed induction generator based on WECS," Int J SystAssurEngManag Springer, pp.1-13, 2019, https://doi.org/10.1007/s13198-019-00844-3.

[25] I.Sami et al., "Integral Super Twisting Sliding Mode Based Sensorless Predictive Torque Control of Induction Motor," IEEE Access, vol. 8, pp. 86740-186755, 2020.

[26] H. B. Merabet et al., "Power quality enhancement in electricity grids with wind energy using multicell converters and energy storage," J. Renewable Sustainable Energy, vol. 11, pp. 1-15, 2019, https://doi.org/10.1063/1.5043292.

[27] A.S. Badawi et al., "Novel technique for hill climbing search to reach maximum power point tracking," International Journal of Power Electronics and Drive System (IJPEDS), vol. 11, pp. 2019-2029, 2020.

[28] M. A. B. Bensahila et al., "Modeling, Simulation and Control of a DFIG for wind energy conversion systems," International Journal of Power Electronics and Drive System (IJPEDS), vol.11, pp. 1197-1210, 2020.

[29] K. Bedouda et al., "Adaptive Fuzzy Gain Scheduling of PI Controller for control of the Wind Energy Conversion Systems," Energy Procedia, vol. 74, pp. 211-225, 2015.

[30] J. Zhang and S. Xu, "Application of Fuzzy Logic Control for Grid-Connected Wind Energy Conversion System, Fuzzy Logic-Tool for Getting Accurate Solutions,” Elmer P. Dadios, IntechOpen, 2015, https://dx.doi.org/10.5772/59923. 